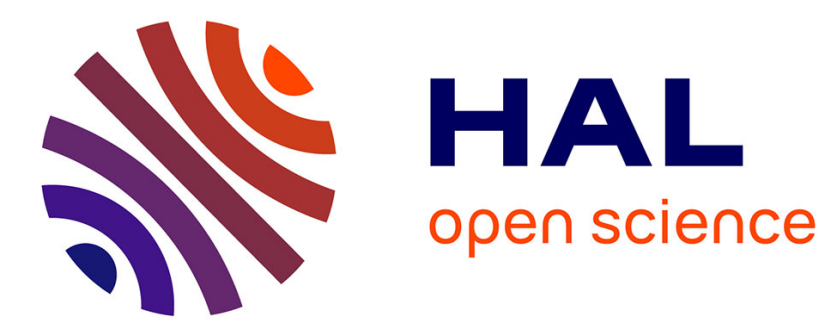

\title{
Charge density wave phenomena in the family of two dimensional monophosphate tungsten bronzes: (PO2)4(WO3)2 m
}

\author{
P. Foury, Jean Pouget, Z. Teweldemedhin, E. Wang, M. Greenblatt, D. Groult
}

\section{To cite this version:}

P. Foury, Jean Pouget, Z. Teweldemedhin, E. Wang, M. Greenblatt, et al.. Charge density wave phenomena in the family of two dimensional monophosphate tungsten bronzes: (PO2)4(WO3)2 m. Journal de Physique IV Proceedings, 1993, 03 (C2), pp.C2-133-C2-136. 10.1051/jp4:1993226 . jpa00251309

HAL Id: jpa-00251309

https://hal.science/jpa-00251309

Submitted on 1 Jan 1993

HAL is a multi-disciplinary open access archive for the deposit and dissemination of scientific research documents, whether they are published or not. The documents may come from teaching and research institutions in France or abroad, or from public or private research centers.
L'archive ouverte pluridisciplinaire HAL, est destinée au dépôt et à la diffusion de documents scientifiques de niveau recherche, publiés ou non, émanant des établissements d'enseignement et de recherche français ou étrangers, des laboratoires publics ou privés. 


\title{
Charge density wave phenomena in the family of two dimensional monophosphate tungsten bronzes: $\left(\mathrm{PO}_{2}\right)_{4}\left(\mathrm{WO}_{3}\right)_{2} \mathrm{~m}$
}

\author{
P. FOURY, J.P. POUGET, Z.S. TEWELDEMEDHIN*', E. WANG* ${ }^{*}$ M. GREENBLATT ${ }^{*}$ and \\ D. GROULT ${ }^{* *}$
}

Laboratoire de Physique des Solides, CNRS LA 2, Université Paris-Sud, 91405 Orsay, France

" Dept. of Chemistry, Rutgers, the State University of New Jersey, New Brunswick, NJ 08903, U.S.A.

** Laboratoire CRISMAT, CNRS URA 1318, ISMRA, 14050 Caen, France

\begin{abstract}
:
The monophosphate tungsten bronzes with pentagonal tunnels $\left(\mathrm{PO}_{2}\right)_{4}\left(\mathrm{WO}_{3}\right)_{2 \mathrm{~m}}$ form a family of $2 \mathrm{D}$ conductors composed of $\mathrm{ReO}_{3}$-type layers of $\mathrm{m}$ oxygen sharing $\mathrm{WO}_{6}$ octahedra belonging to infinite chains running along the non equivalent $\mathbf{a}$ and $\mathbf{a} \pm \mathbf{b}$ directions. $\mathrm{X}$-ray diffuse scattering experiments show that these chains are subject to charge density wave (CDW) instabilities. It is found that the leading $\mathrm{CDW}$ instability changes from chains along $\mathrm{a}$ in the $\mathrm{m}=4$ member to chains along atb for larger values of $m$. In the $m=4$ and $m=6$ bronzes the CDW wave vector, stabilized below each Peierls like transition, leads to a common nesting between differently oriented 1D Fermi surfaces (FS) associated with these chains. Two and three successive CDW transitions, corresponding to a hierarchy of FS nestings, are observed in these members. The CDW modulation observed in the $\mathrm{m}=$ $7,9,10$ and 11 bronzes presents a large number of harmonics, and in $m=7$ its amplitude shows unexpected hysteresis phenomena. It is suggested that these features could be the structural fingerprint of an electron localization, possibly due to the reduction of screening effects when the average number of electron per tungsten, $2 / \mathrm{m}$, decreases with increasing $\mathrm{m}$.
\end{abstract}

\section{Introduction:}

Low dimensional conductors have been extensively studied because of their anisotropic electronic properties and their instability towards the formation of charge density wave (CDW), spin density wave or superconducting ground states which can be in competition in very rich phase diagrams. Because of their anisotropic structures, the transition metal oxides and bronzes belong to this class of materials. One dimensional conductors (1D) such as the blue bronzes $\mathrm{AMo}_{0.3} \mathrm{O}_{3}(\mathrm{~A}=\mathrm{K}$, $\mathrm{Rb}, \mathrm{Tl}$ ) which present a Peierls transition have been particularly studied because the CDW can collectively slide under the action of an external electric field [1]. Recently, the interest for 2D conductors has been renewed and a large number of works has been devoted to the oxide $\mathrm{Mo}_{4} \mathrm{O}_{11}$ and the purple bronzes $\mathrm{A}_{\mathrm{X}} \mathrm{Mo}_{6} \mathrm{O}_{17}(\mathrm{~A}=\mathrm{Na}, \mathrm{K}, \mathrm{Tl} ; \mathrm{X} \approx 1)$ [1]. CDW ground states have been observed and related to the nesting properties of hidden 1D portions of their Fermi Surface (FS) [2]. The purpose of this paper is to present some general structural properties of a new series of 2D tungsten bronzes $\left(\mathrm{PO}_{2}\right)_{4}\left(\mathrm{WO}_{3}\right)_{2 \mathrm{~m}}$ which possess a layer structure, very similar to that of the purple bronzes and $\mathrm{Mo}_{4} \mathrm{O}_{11}$. 


\section{Structural arrangement : Hidden one-dimensionality}

$\left(\mathrm{PO}_{2}\right)_{4}\left(\mathrm{WO}_{3}\right)_{2 \mathrm{~m}}$ crystallizes in the ortorhombic system (for $\mathrm{m} \neq 5$ ). The crystal structure detailed in ref. [3] is built with $(\mathrm{a}, \mathrm{b}) \mathrm{ReO}_{3}$-type slabs of comer sharing $\mathrm{WO}_{6}$ octahedra terminated by $\mathrm{PO}_{4}$ tetrahedra. The connection between $\mathrm{WO}_{6}$ and $\mathrm{PO}_{4}$ groups creates pentagonal tunnels. The thickness of the slab increases with $\mathrm{m}$. An X-ray diffuse scattering investigation of the bronzes of $\mathrm{m}=4,6$ and 7 already reveals at room temperature (RT), different sets of diffuse segments. One set observed in all the members, corresponds to diffuse segments perpendicular to the $\mathbf{a} \pm \mathbf{b}$ directions (oblique arrows figure 2a). Computer simulations of X-ray patterns demonstrate that these diffusions are due to $1 D$ pretransitionnal fluctuations along the $\mathbf{a t b}$ directions (see figures la and $\mathrm{b}$ ). The corresponding chains are constituted of clusters of $\mathrm{m}$ "basal" oxygen sharing $\mathrm{WO}_{6}$ octahedra connected in a stair case manner by their axial oxygen. The modulation consists in a rigid displacement of this cluster with a polarisation $\mathbf{u}$ which gradually evolves from the chain direction to the cluster direction when $\mathrm{m}$ increases (see table). The other set of diffuse lines, observed for $\mathrm{m}=4$ and 6 (horizontal arrows figure 1a) is perpendicular to the a direction and due to 1D pretransitional fluctuations along the a direction. The corresponding chains are composed of stripes of $\mathrm{m}$ corner sharing $\mathrm{WO}_{6}$ octahedra.

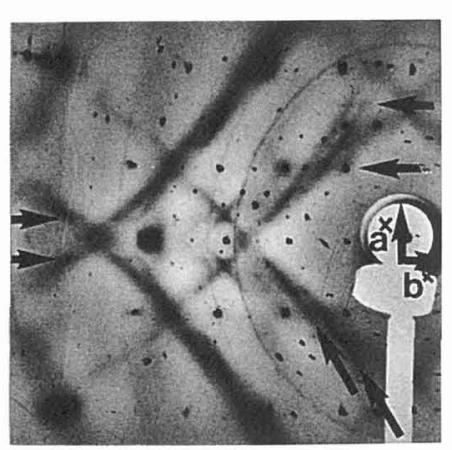

(a)

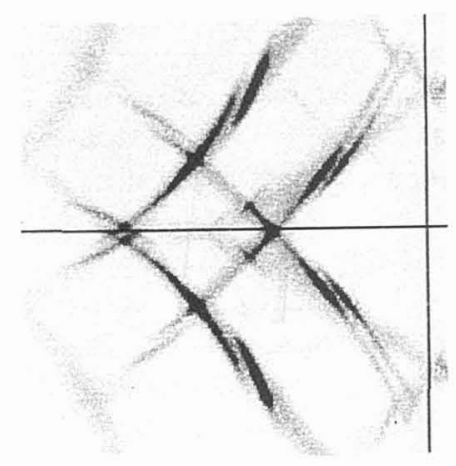

(b)

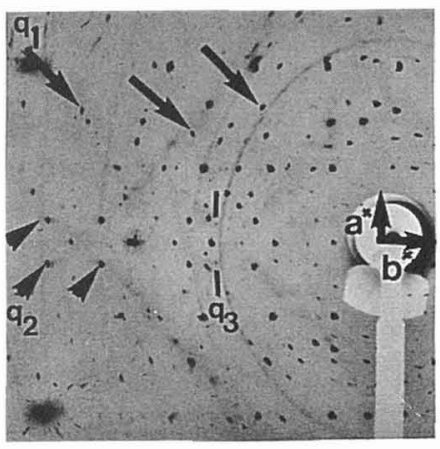

(c)

Fig. 1: X-ray patterns taken at $200 \mathrm{~K}$ (a) and $20 \mathrm{~K}$ (c) in $\mathrm{m}=6$. (b) is the computer simulation of (a).

In addition, band calculations ${ }^{[4]}$ show that the conducting electrons belong to $5 \mathrm{~d}_{2 \mathrm{~g}}$ orbitals with preferential overlap along the $\mathbf{a}$ and $\mathbf{a t b}$ chain directions. So, the electronic structure is basically composed of 3 quasi-1D partially filled bands with 2 electrons per half unit formula $(2 / \mathrm{m}$ electron per tungsten). A schematic representation of the Fermi Surface (FS) is given figure 2.

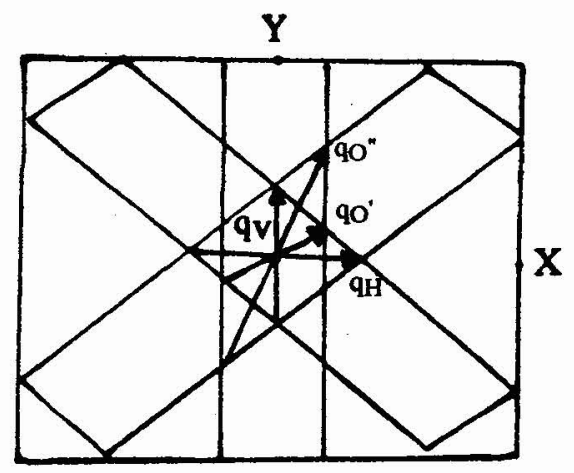

Fig.2 : Schematic FS of $\left(\mathrm{PO}_{2}\right)_{4}\left(\mathrm{WO}_{3}\right)_{2 \mathrm{~m}}(\mathrm{~m}>2)$ where the $4 \mathrm{MNWV}$ are indicated. 


\section{CDW phase transitions:}

For all the members of the series, periodic lattice distorsions have been observed but with characteristics depending upon the value of $\mathrm{m}$. Two main behaviors which will be analysed separatly in the following have been observed.

\section{$\mathrm{P}_{4} \mathrm{~W}_{8} \mathrm{O}_{32}$ and $\mathrm{P}_{4} \mathrm{~W}_{12} \mathrm{O}_{44}$ :}

Upon cooling, the diffuse lines quoted above condense into satellite reflections at the reduced wave vector $\mathrm{q}_{\mathrm{i}_{\mathrm{m}}}$ (i for the $\mathrm{i}^{\text {th }}$ transition of the $\mathrm{m}^{\text {th }}$ member) from the main Bragg reflections (see table). For these two compounds, 2 and 3 successive second order structural transitions with incommensurate modulation are respectively observed. Each kind of satellite reflections appear at the intersections of different sets of diffuse lines (see figure $1 \mathrm{c}$ in the case of $\mathrm{m}=6$ ). These structural transitions give rise to conductivity and magnetic susceptibility anomalies $[5,6]$. They correspond to successive CDW instabilities of the FS. The CDW stabilized at the upper transition corresponds to a maximum nesting of the FS. There are 4 Maximum Nesting Wave Vectors (MNWV) defined figure 2. For $m=6, q 16$ corresponds to $q_{H}$ while for $m=4, b^{*}-q_{14}$ to $q_{o} "$. This difference between the wave vectors is probably due to the fact that the leading CDW instability changes from chain $\mathrm{a}$ in the $\mathrm{m}=4$ member to chains $\mathbf{a} \pm \mathbf{b}$ for $m \geq 6$. If the high temperature (HT) description of the FS is kept, the mechanism of stabilisation for the second and third transition is similar : for $m=6 q_{26}$ and $q_{36}$ correspond to $\mathrm{qo}^{\prime \prime}$ and $\mathrm{qo}^{\prime}$ while for $\mathrm{m}=4 \mathrm{q}_{24}$ corresponds to $\mathrm{qH}_{\mathrm{H}} \equiv \mathrm{qo}^{\prime}$ because of the special value $1 / 3$ of $2 k_{F}$ for the chains $\mathbf{a}$ and $\mathbf{a} \pm \mathbf{b}$. The modulation wave vector of each transition corresponds to one MNWV defined figure 2. No structural modulation with the wave vector $q_{v}$ is observed probably because there is no chain running along $b$.

\begin{tabular}{|c|c|c|c|c|}
\hline$\left(\mathrm{PO}_{2}\right)_{4}\left(\mathrm{WO}_{3}\right)_{2 \mathrm{~m}}$ & $\mathrm{~T}_{\mathrm{c}}(\mathrm{K})$ & $\mathbf{g}_{\mathbf{c}}$ & $\alpha_{\text {chain }}$ & $\alpha_{\text {segment }}$ \\
\hline $\mathrm{m}=4$ & $\begin{array}{l}80( \pm 1) \\
52( \pm 1)\end{array}$ & $\begin{array}{l}\mathrm{q}_{1_{4}}=(0.330(5), 0.295(5), ?) \\
\mathrm{q}_{24}=(0.340(5), 0, ?)\end{array}$ & $16^{\circ}\left( \pm 10^{\circ}\right)$ & $35\left( \pm 10^{\circ}\right)$ \\
\hline $\mathrm{m}=6$ & $\begin{array}{l}120( \pm 1) \\
62( \pm 1) \\
\approx 30\end{array}$ & $\begin{array}{l}\mathrm{q}_{16}=(0.385(5), 0,0) \\
\mathrm{q}_{26}=(0.310(5), 0.295(5), ?) \\
\mathrm{q}_{36}=(0.29(1), 0.12(1), ?)\end{array}$ & $25^{\circ}\left( \pm 10^{\circ}\right)$ & $30^{\circ}\left( \pm 10^{\circ}\right)$ \\
\hline $\mathrm{m}=7$ & $\begin{array}{l}188( \pm 1) \\
60( \pm 2)\end{array}$ & $\begin{array}{l}\mathrm{pq}_{17} \quad \mathrm{p}=1,2,3,4,5,6,7, . . \\
\mathrm{q}_{17}=[0.260(3), 0.073(3), 0.27(5)] \\
\mathrm{rq} 2_{7} \quad \mathrm{r}=1,3,5, \ldots \ldots \\
\mathrm{q}_{27}=[0.12(1), 0.03(1), 0.15(5)]\end{array}$ & $35^{\circ}\left( \pm 10^{\circ}\right)$ & $15^{\circ}\left( \pm 10^{\circ}\right)$ \\
\hline $\mathrm{m}=9$ & above RT & $\begin{array}{l}\mathrm{pq}_{19} \quad \mathrm{p}=1,2,3 \ldots \\
\mathrm{q}_{19}=(1 / 6,0,0)\end{array}$ & $?$ & $?$ \\
\hline $\mathrm{m}=10$ and 11 & above RT & $\begin{array}{l}\mathrm{pq}_{1_{10}} \quad \mathrm{p}=1,2,3,4 \ldots \\
\mathrm{q}_{1_{10}}=(1 / 7,0,0)\end{array}$ & $?$ & $?$ \\
\hline
\end{tabular}

Table : Critical temperatures and modulation wave vectors for each member of the series $\left(\mathrm{PO}_{2}\right)_{4}\left(\mathrm{WO}_{3}\right)_{2 \mathrm{~m}} \cdot \alpha_{\text {chain }}$ and $\alpha_{\text {segment }}$ are the angle of $\mathbf{u}$ with respect to the chain and segment directions respectively. 


\section{$\left(\mathrm{PO}_{2}\right)_{4}\left(\mathrm{WO}_{3}\right)_{2} \mathrm{~m}$ with $\mathrm{m} \geq 7$ :}

In $\mathrm{P}_{4} \mathrm{~W}_{14} \mathrm{O}_{50}(\mathrm{~m}=7)$, two structural transitions are also observed upon cooling. However in contrast to the $m=4$ and 6 members, the satellite reflections of the upper transition exhibit very unusual behaviors. Firstly, the modulation is triply incommensurate and shows a large number of harmonics. Secondly, the thermal dependence of the satellite intensities present anomalies and giant hysteresis (also observed in resistivity measurements [7]). The lower transition corresponds to dimerization of the $q_{17}$ modulated structure $\left(q_{27} \approx q_{17} / 2\right)$. The $m=8$ member also develops $C D W$ instabilities below $\mathrm{RT}$. $\left(\mathrm{PO}_{2}\right)_{4}\left(\mathrm{WO}_{3}\right)_{2} \mathrm{~m}$ with $\mathrm{m} \geq 9$ exhibits already at $\mathrm{RT}$ a superstructure which can be described as a commensurate modulation $\mathrm{q}_{1 \mathrm{~m}}$ with multiple harmonics $\mathrm{pq} 1 \mathrm{~m}$. From $\mathrm{m}=9$ to $\mathrm{m}=10$, the wave vector $q_{1}$ change from $1 / 6 a^{*}$ to $1 / 7 a^{*}$, a value which is also observed for $m=11$ and thus seems to have a special stability. The common feature of the modulations observed in the tungsten bronzes with high $\mathrm{m}$ is the presence of a large number of harmonics. The harmonics correspond to a structural distortion with a rapidly changing amplitude in direct space. This could be the structural fingerprint of an electron localization phenomena achieved either by strong electron-phonon or/and by strong electron-electron interactions. The effect of Coulomb interactions could be particularily relevant in the tungsten bronzes, because a decrease of the screening effects is expected when the number of electron per tungsten $(2 / \mathrm{m})$ decreases with increasing $m$ (in addition the $m=2$ bronze $\mathrm{PWO}_{5}$ is localized and exhibits an antiferromagnetic ground state ${ }^{[8]}$ ).

\section{Concluding remarks :}

The monophosphate tungsten bronzes show very rich physical phenomena related to the hidden one dimensionality of their electronic structure. The most intriguing feature is the observation of a hierarchy of CDW ground states whose characteristics evolve with the thickness of the slab (i.e. with $\mathrm{m}$ ). The CDW instabilities observed in $\mathrm{m}$ bronzes with $\mathrm{m}=4$ and $\mathrm{m}=6$, have some resemblance with those previously reported in $\mathrm{Mo}_{4} \mathrm{O}_{11}$ and the purple bronzes $\mathrm{A}_{\mathrm{x}} \mathrm{Mo}_{6} \mathrm{O}_{17}$. Instabilities observed in the high $\mathrm{m}$ bronzes are more unusual and require further studies. A full account of this structural work can be found in ref. [9].

\section{References:}

[1] See for example C. SCHLENKER (Editor), Low Dimensionnal Properties of Molybdenum Bronzes and Oxides, Kluwer Academic Publisher, 1989

[2] M.H. WHANGBO, E. CANADELL, P. FOURY, J.P. POUGET, Science 252 (1991) 96

[3] B. DOMENGES, F. STUDER and B. RAVEAU, Mater. Res. Bull. 18, (1983) 669

[4] E. CANADELL and M.H. WHANGBO, Chem. Rev. 91 (1991) 965

[5] E. WANG, M; GREENBLATT, I.E.I. RACHIDI, E. CANADELL, M.H. WHANGBO and S. VADLAMANNATI, Phys. Rev. B39, (1989) 12969

[6] Z.S. TEWELDEMEDHIN, K.V. RAMANUJACHARY and M. GREENBLATT, Phys. Rev.B46, Vol. 12, (1992), 7897

[7] A. RÖTGER, C. SCHLENKER, J. DUMAS, E. WANG, Z.S. TEWELDEMEDHIN and M. GREENBLATT, Synth. Metals, 56 (1993) 2670

[8] Z.S. TEWELDEMEDHIN, K.V. RAMANUJACHARY and M. GREENBLATT, J. Solid State Chem. 95 (1991) 21

[9] a) P. FOURY, J.P. POUGET, E. WANG and M. GREENBLATT Europhys. Lett. 16 (1991) 485

b) P. FOURY, J.P. POUGET, Z.S. TEWELDEMEDHIN, E. WANG and M.

GREENBLATT Synth. Metals, 56 (1993) 2605

c) P. FOURY and J.P. POUGET, Review of Modern Physics, under press (1993) 